complete deductions from the measures of sun-spots and facula in that year, if they can be prepared for press in time, leaving the complete results for the years 1873 to 1875 to be included in the next volume; the areas, as distinct from positions, having been already printed in the volumes for 1874 and I 875 .

The ustual magnetical and meteorological observations have been carried on, and considerable progress made with their reduction.

The following are the principal results for magnetic elements in the year 1877 :-

A pproximate mean westerly declination $18^{\circ} 57^{\prime}$.

Mean horizontal force

$33^{\circ} 901$ (in English units). 1. 799 (in metric units).

$\{673846$ (by 9-inch needles) 673954 (by 6 -inch needles). 674040 (by 3 -inch needles).

Under the head of Extraneous Work, information is given as to the reduction of the Transit of Venus observations.

At the date of the last Report the determination of the longitudes of the British stations was not quite complete (that of Kerguelen being then imperfect). But, under a demand from the House of Commons, a strong effort was made to finish all introductory calculations, and to effect computations of solar parallax by comparing all eye-observations of ingress of Venus among themselves, and all eyc-observations of cgress of Ventus among themselves. The different stages of phenomena at the noress were discriminated by Capt. Tumman with great care, and Sir George Airy belicves with great gencral success, althongh Capt. Tupman himself has been induced lately to modify his intcrpretation of the observers' language in one or two instances. Finally, a report was macie to the Government on July 5 , giving as the mean result for mean solar parallax $8^{\prime \prime} \cdot 76$, the results from ingress and from egress, however, differing to the extent of $\mathrm{O}^{\prime \prime} \cdot \mathrm{I}$ I. A more complete calculation by the Astronomer-Royal, including in one series the observations both at ingress an ! at egress, and recognising the possible errors of R.A. and N.P.D., gave scnsibly the same mean result for parallax. This is liable to no error except from the interpretation of observers language. All has subsequently been re-examined by Capt. Tupman; different interpretations have, in a few instances, been put on the records; several observations from colonial stations have been combined; instead of using different phases in the obscrvations (both of ingress and of egress), attempts have been macle to ascertain the one phase of "contact of limbs ;" the notes of a few unpractised observers have been rejected, and the result for parallax has been increased to $S^{\prime \prime} \cdot S_{2}$ or $\mathcal{S}^{\prime \prime} \cdot S_{3}$.

The numerous photographs taken at the various stations had becn carefully measured by Mr. I3urton, and have since been re-measured by Capt. Tupman; and (by photographs of $\mathrm{Mr}$. De la Rue's scale of equal parts) the measure of photographic distortion had been well ascertained. But the results from photography have disappointed Sir George Airy much. The failure has arisen perhaps sometimes from irregularity of limb, or from atmospheric distortion, but more frequently from faintness and from want of clear definition. Many photographs which to the eye appeared good, lost all strength and sharpness when placed under the measurino microscope. It was once remarked to Sir George Airy, "You might as well try to measure the zodiacal light." A final result, $\delta^{\prime \prime} \cdot 17$, the report states, was obtained from Mr. Burton's measures, and 8".08 from Capt. 'Tupman's.

The Report next alludes to the progress made in the numerical lunar theory. The developments of the effect of every possible error (expressed as a symbolical variation) in the co-efficients and arguments of the assumed lunar ordinates upon every term in the three fundamental expansions of-(I) Areas in the ecliptic, (2) Radial forces in the ecliptic, (3) Forces normal to the ecliptic-have been computed and printed. The corresponding solar perturbing forces have been computed entirely for the first of these (care being taken to extend the decimal calculation further for those terms whose effect may probably be increased in solution of the equations, a process in which many figures are almost necessarily wasted), and partially for the second and third. Until all have been completed the Astronomer-Royal cannot draw any positive inference from the comparison of these terms with those of the ordinate expansions; but a cursory collation of those relating to the areas led him to suppose that there might be some error in the computations of the amnual equation and related terms. A most jealous re-examination has, however, detected nothing, and has confirmed Sir George Airy's belief in the general accuracy of the numerical computations.

Finally, Sir George Airy strongly urges upon the Board the necessity for the erection of a separate room for the library of the Observatory.

\section{COSMICAL RESULTS OF THE MODERN HEAT THEORY}

IN the Sitzungsberichte derWiener Akadkmie der Wissenschaflen, Herr J. Loschmidt has published a treatise on the equilibrium of temperature in a system of heavenly bodies with regard to gravitation, from which we note the following highly interesting details :- "Sir W. Thomson and Clausius simultaneously." drew from their researches the surprising conclusion that the whole universe at some definite period, however remote, would infallibly come to an end. First, all ponderous masses in the universe will eventually have united to one enormous heavenly body; and secondly, upon this body all visible motion will have ceased, all forces having changed to mere molecular motion, which in the shape of heat of universally uniform temperature will be spread in this mass. This state of general death will then last eternally." Herr Loschmidt, in the course of his researches, has arrived at widely different conclusions. He begins by adopting the general view that the sun is in a state of slow progression of cooling, and that the time will unavoldably arrive when his surface will have solidified, long after all his planets have fallen in upon him, and after his upper and partly also his lower strata have assumed very nearly the temperature of the surround. ing universal space. But granting that thus a period of rest and death will have arrived for our solar system, Herr Loschmidt maintains, at the same time, that this period cannot be of unlimited duration; the state of things just described can, according to his views, not be a state of equilibrium. "The previuus liquid state of the sun has caused a continued mixture of the warmer parts near the centre with the colder ones near the suriace. Thus, however, the equilibrium of temperature, which requires a certain increase of temperature towards the interior, was rendered impossible. At the moment of solidification of the external layers the deeper ones will be far colder than the theory of the state of equilibrium demands. Because, according to this theory, the surface should have the temperature of universal space (about - $140^{\circ} \mathrm{C}$. according to Pouillet), but this temperature should rapidly increase towards the interior, reaching at the centre the enormous figure of $250,000,000^{\circ} \mathrm{C}$. And it is just because at the moment of the beginning of solidification of the sun no such distribution of temperature took place in the interior, that the state above referred to cannot be of eternal duration. During an extremely long period, in spite of the low temperature of his surface, the solidifying sun will constantly absorb radiant heat from the store in the universe and will concentrate this heat in his interior. We suppose, for a moment, that it would be physically possible that this process of absorption is carried on to the end without the inclosed and dissociated gases in the interior breaking through the solidified surface or crust on account of their enormous tension. We then calculate the amount of heat accumulated in the end and find that it would easily suffice to raise the entire solar mass to $\frac{2}{5}$ ths of that temperature which the state of equilibrium demands at the centre, viz,, to $100,000,000^{\circ} \mathrm{C}$. This figure is raised if the average molecule of the solar mass, instead of being supposed to be of the density of oxygen, is taken to be of the density of carbonate of lime; in that case it would be $125,000,000^{\circ} \mathrm{C}$. We may compare these results to the quantity of heat which was produced during the condensation of the solar system from the cosmical nebula, according to the theory of Laplace and Kant. Helmholtz has calculated that the heat thus generated would suffice to raise the solar mass to a temperature of $28,611,000^{\circ} \mathrm{C}$., if it is supposed to have the heat capacity of water. If, instead of water, other substances are taken as starting points, this temperature is considerably raised so in the case of carbonate of lime or silicic acid, the heat capacity of which is $0^{\circ} 2$, the resulting temperature would be $140,000,000^{\circ} \mathrm{C}$

"The close correspondence of both amounts speaks in favour of a periodicity in the history of solar systems. In the first portion of its cosmical period the dark solidified body absorbs heat

I [Clausius verified Thomson's statements about dissipation just as he verified (after experiment had proved it) J. Thomson's statement of the loweriog of the freezing-point of water by pressure. Some Germans still call this "simu!taneous discovery." Helmholtz, at least, does not.-ED.] 
from universal space, and thus the temperature in its interior is gradually increased to an immeasurable extent. Then the moment arrives when the exterior crust can no longer resist the rising pressure of the inclosed masses, which have, of course, become gaseous. An explosion must result. The greater part of the mass which is converted into gas is dispersed over a great space, and thus by far the greater part of the accumulated heat is converted into gravitation and force of rotation o the dispersed masses. Now the second portion of the solar period begins, which, as a process of condensation of cosmical nebula and subsequent slow cooling of the bodies formed by this condensation, has been frequently discussed since the days of Laplace."

This is I Ierr Loschmidt's idea of the typical course of a cosmical period, if fully developed according to the laws of heat. But he thinks that it is highly probable that this full development can be but rarely realised in the case of a solar system, since the duration of the heat-absorption will generally find a premature end in the impossibility of the external crust resisting the enormous pressure of the inclosed gases until the maximum of temperature is arrived at. "Upon our sun, for instance, in a state of equilibrium of temperature, the surface temperature would be $-140^{\circ} \mathrm{C}$., while at a depth of half a (German) mile we already would find a temperature of $3,000^{\circ} \mathrm{C}$. Here all known substances would be in a state of liquid incandescence. The solid crust could therefore not be thicker than half a (German) mile. In this case, therefore, the typical course described would evidently be interrupted prematurely by an explosion.

"The consequences of a solar eruption of this kind are naturally very different under differenty conditions. Thus with a comparatively small accumulation of heat and corresponding low tension, the result would be simply the return to incandescence of a dark heavenly body, while with greater concentration of heat sone portions 'may be separated from the principal mass and carrled to great distances, where, forming themselves into planets, they would revolve round the principal mass in elliptical orbits. This theory, therefore, easily explains the origin of planets, like those of our system, and the manner in which they were carried to their respective places and are provided with heir forces of rotation and revolution, and also how after all in the principal solar mass a quantity of heat would remain, which would cause a far higher temperature upon its surface than exists at present upon our sun. The principal solar mass would thus be again enabled to radiate light and heat to its planets and into the universe, until again the moment of solidification and rebegimning of absorption of heat has arrived. The total resuit under the most varying circumstances always remains the same : periodicity of the dynamical solar phenomena.

"If finally we look for proofs for our theory in the heavens, we direct our attention to dark burnt-out suns on the one hand and to suddenly appearing new suns on the other. It is strange that modern times have given examples of both classes of phenomena. As a representative of the first class we have the dark companion of Sirius, calculated in advance by Bessel from the disturbances, and actually seen by A. Clark and Pond in I862. This enormous mass has only just been rendered visible by the most powerful instruments, although it is nearly seven times the size of our sun. A second example is the companion of Procyon which, though calculated with certainty, has not yet been seen on account of its still greater darkness. Examples of the other class we have in the well-known new stars of Tycho Brahe and Kepler, besides the new star in Corona of 1866 and the one recently seen by Schmidt and others in Cygnus (December, 1876). In both these latter cases eruptions of incandescent hydrogen were proved beyond doubt by spectral observations."

\section{THE METEOR}

A METEOR of unusual brilliance was seen of the "fire-ball" type on Friday night by several correspondents. All agree that the time was about 9.50 , the moon at the time being in her second quarter, and about $30^{\circ}$ above the horizon in the west-south. west. At Twickenham its observed course was from south-west to north-west passing the azimuth of the moon at the time $69^{\circ}$ from south to west, at an altitude of about $14^{\circ}$, its path being nearly parallel to the horizon, or declining very slightly towards its disappearance, which was sudden, at $9 \mathrm{~h} .52 \mathrm{~m}$. 30s. Greenwich mean time. Colour, bright emerald green ; apparent diameter, about one-third of that of the moon, this being the greater diameter of the elliptical figure. The light thrown by the meteor in this locality was decidedly green. Mr. Lecky, writing from the Scientific Club, states that the course of the meteor was about $90^{\circ}$ below the moon, its motion very slow, and it became extinguished rather suddenly, without any apparent bursting, when it had passed about the same distance to the north of the moon. The meteor appeared to Mr. Lecky to be about the same size as the moon. Mr. L. J. Whalley saw it from the Brompton Road. Facing west he saw it pass from south to north, its path being inclined downwards at a few degrees to the horizon, and its altitude about $30^{\circ}$. The fore-part appeared rounded in shape, and of a bright green colour (like nickel sulphate), whilst the tail tapered off, and was of a red to a purplish tint.

Mr. Walter Fowler saw it from Cambridge. Its path, he states, was from south to north, almost parallel with the horizon, with a slight declination northwards. During its course, which lasted about twenty seconds, it emitted innumerable sparks variegated in colour.

Another correspondent saw it from London Street, Greenwich. Its apparent altitude, he states, was about $28^{\circ}$ or $30^{\circ}$ above the western horizon, and it passed horizontally over the tops of the houses in a direction about two points to the west of north. He observed it for about three seconds. It appeared in passing under the moon to be about $6^{\circ}$ or $8^{\circ}$ underneath her lower limb, and about the same degree of brightness and equal to it in size. The meteor, he states, had a tail about equal to six or seven diameters of its nucleus; the central part of the tail and the nucleus were of a pale orange hue and fringed with violet rays. The tail was in the line of motion, and was not a perfect cone, but appeared to expand into a fin-like form at the extremity.

Mr. F. J. Richardson, of Dimchurch, near Rugby, observed the meteor, "of considerable size," cross the sky, apparently about $30^{\circ}$ above the horizon. The direction of its path was from south to west, and its colour appeared a mixture of orange and green. It remained visible for about thirty or forty seconds, and then suddenly disappeared.

Mr. R. Langdon, writing from Silverton Station, Devon, states that it moved slowly towards Ursa Major, and exploded a little beyond that constellation. Its colours were, first, very pale blue (nearly white), then deep blue, and finally, the several fragments after explosion were blood.red. Dr. Morison saw it from Jersey. When first seen it was about $30^{\circ}$ from the zenith in a direction nearly due north. The diameter of its disc, which was apparently circulax, was rather more than half that of the full moon, which it far surpassed in brillancy, shining with a beauti ful white light. The meteor descended towards the horizon, leaving a very faint luminous trail behind it, and was lost to sight, while still remaining entire, behind a high wall. It was altogether visible about thirty seconds.

Our Paris correspondent writes that a splendid meteor was seen in the department of Aisne and at Versailles about ten o'clock in the evening, travelling westwards at a small altitucle. It was in diameter about one-sixth that of the moon, the brilliancy admirable, and the tail four or five times the length of the moon's diameter. No noise was heard.

Mr. Denning, of Bristol, writing to the Times, states that the meteor had a very long path, almost horizontal, from east to west, which it traversed with a gradual motion, casting off a short train of sparks as it sailed along, and showing sensilyle variations in the brilliancy of its pear-shaped nucleus. The position of the observed part of its path was noted from $\mathrm{I}^{\circ}$ above the star Spica Virginis to $6^{\circ}$ above the moon, but to inclucle the whole extent of its visible course the line must be extended in each direction, and have a length of at least $75^{\circ}$ from, say, slightly below Alpha Libræ to slightly above Alpha Leonis, running almost parallel with the ecliptic. The meteor was considerably brighter than Venus, and perhaps equal to a body onefourth of the moon's diameter. Mr. H. Middleton Rogers states that while walking along a footpath close to Knole Park, he saw it passing apparently from south to north, very nearly parallel to the horizon, with a very slight declination towards the north. When he first saw it it was about $5^{\circ}$ from the moon, (taking the moon's diameter roughly at haif a degree.) It passed slowly along about $3^{\circ}$ below the moon, or about $30^{\circ}$ above the horizon, and continued its course for about $20^{\circ}$ further towards the north, when it suddenly disappeared. The light was of a very pale green, as nearly as possible like the light of a glow. worm highly intensified. As it passed under the moon its brilliancy caused the moon to look of a muddy yellow colour- 